\title{
La acción de los ugetistas en la Organización Internacional del Trabajo: contrarrestar el sindicalismo franquista en el mundo (1969-1976)*
}

\author{
Enrique Berzal de la Rosa ${ }^{1}$ \\ Universidad de Valladolid
}

RESUMEN: La intervención de los socialistas europeos y de los sindicatos tuvo un impacto favorable en el establecimiento de una oposición enérgica y en la deslegitimación del régimen de Franco, tanto en el interior como en el exterior de España. El estudio de la dimensión internacional de la UGT durante el franquismo es fundamental para entender la supervivencia del sindicato socialista durante el largo periodo de la dictadura, y ayuda a comprender su proceso de reconstrucción en los años 70. La OIT actuó como altavoz de las críticas al régimen franquista y a su sistema sindical, y contribuyó a moderar la represión de la dictadura.

PALABRAS CLAVE: UGT; sindicalismo; oposición; franquismo; OIT.

UGT action at the ILO: counteracting Francoist unionism in the world (1969-1976)

* Este artículo se enmarca dentro del Proyecto de Investigación, dirigido por Manuela Aroca Mohedano, «La trayectoria internacional del sindicalismo socialista Español (18881986)», coordinado por la Fundación Francisco Largo Caballero y financiado por el Ministerio de Economía y Competitividad, Plan Nacional de Investigación I+D+I (HAR2013-44849-P).

Archivos citados: Fundación Anastasio de Gracia-FITEL, Madrid, (FAGFITEL); Fundación Francisco Largo Caballero, Alcalá de Henares, Madrid (FFLC); International Institut of Social History, Ámsterdam (IIHS).

Las limitaciones de espacio y el hecho de centrarnos exclusivamente en la acción de la Unión General de Trabajadores en el marco de la Organización Internacional del Trabajo nos exime de tratar la réplica franquista, cuyas fuentes documentales se encuentran en el Archivo General de la Administración, pero que ya ha sido tratada en profundidad en MATEOS, 1997a y MARTÍNEZ QUINTEIRO, 1997, obras de las que nos hacemos eco a lo largo del texto.

1 berzaldelarosa@hotmail.com, ORCID iD: https://orcid.org/0000-0002-5716-8707. 
ABSTRACT: The intervention of European Socialists and trade unions had a favourable impact on the establishment of a meaningful opposition and on the delegitimising of Franco's regime both in Spain and abroad. The international dimension is fundamental to understanding the survival of UGT during Francoism; it also contributed to the reconstruction of the Union in the early Seventies. The International Labour Organization was a staunch critic of the Francoist regime and its trade-union system, and helped moderate the repression exercised by the dictatorship.

KEY WORDS: UGT; trade unions; opposition; Francoism; ILO.

CÓMO CITAR ESTE ARTÍCULO/CITATION: Berzal de la Rosa, Enrique, «La acción de los ugetistas en la Organización Internacional del Trabajo: contrarrestar el sindicalismo franquista en el mundo (1969-1976)», Hispania, 78/259 (Madrid, 2018): 439467. https://doi.org/10.3989/hispania.2018.012.

En 1944, la Organización Internacional del Trabajo (OIT) adoptó la Declaración de Filadelfia, denominación que hace referencia a lo acordado en la Conferencia Internacional celebrada en dicha ciudad, que otorga primacía a los principios sociales en la política internacional al establecer que «el trabajo no es una mercancía», la libertad de expresión y de asociación «es esencial para el progreso constante», la pobreza constituye un peligro para la prosperidad de todos y «todos los seres humanos, sin distinción de raza, credo o sexo, tienen derecho a perseguir su bienestar material y su desarrollo espiritual en condiciones de libertad y dignidad y de seguridad económica y en igualdad de oportunidades $»^{2}$. Dicha Declaración fue incorporada a la Constitución de la OIT en 1946, año además en el que la Organización pasa a ser una agencia especializada de la ONU. La composición tripartita, establecida en el artículo 3 de su Constitución fundacional, constituye la principal característica de la $\mathrm{OIT}^{3}$; de este modo, cada país está representado por dos delegados gubernamentales, un delegado de los patronos y un representante de los trabajadores.

En el periodo cronológico que aborda este artículo, la Organización Internacional del Trabajo alcanzará los 126 miembros, desde los 55 que la componían en 1944. Su cometido principal, consistente en la elaboración de normas bajo forma de convenios o recomendaciones que deberían servir de modelo a las legislaciones sociales de los gobiernos, explica que a pesar de no tener un poder coercitivo directo, sí posea una enorme incidencia en términos de con-

2 RODGERS, LEE, SWEPSTON y VAN DAELE, 2009: 7-8, 41-42, 48-49 y 271-274.

3 «La Conferencia General [...] se compondrá de cuatro representantes de cada uno de los Miembros, dos de los cuales serán delegados del gobierno y los otros dos representarán, respectivamente, a los empleadores y a los trabajadores de cada uno de los Miembros», señala dicho artículo. 
dena moral. De ahí la importancia que en todo momento dio la Unión General de Trabajadores (UGT) a la presencia, aunque fuera mediante organización interpuesta, en la OIT, a la que consideraba un privilegiado altavoz de sus demandas y un instrumento de presión muy eficaz para desacreditar el sindicato vertical y denunciar la vulneración de las libertades sindicales en la España de Franco.

No podemos olvidar, a este respecto, que la prioridad otorgada tras la guerra a los derechos humanos, explicitada en la Declaración Universal de los Derechos Humanos de Naciones Unidas (1948), supuso un impulso muy eficaz para los derechos fundamentales en el trabajo que preconizaba la OIT. Precisamente, en relación directa con esta temática se aprobaron, en primer lugar, el Convenio 87 (1948) sobre «libertad sindical y protección del derecho de sindicación», del que se derivará el principio contenido en la Declaración de Derechos Humanos de la Organización de las Naciones Unidas (ONU): «Toda persona tiene derecho a fundar sindicatos y a sindicarse para la defensa de sus intereses»; y, en segundo lugar, el convenio 98 sobre el derecho de sindicación y de negociación colectiva (1949). También jugó a favor de los valores que defendía esta organización intergubernamental el contexto económico de la postguerra, caracterizado por el rápido crecimiento y el pleno empleo de los países industrializados, el desarrollo del estado de bienestar en los países de la Europa Occidental, la fortaleza de los sindicatos, la mejora de las condiciones laborales, la mayor regulación del mercado de trabajo y, en términos generales, una relativa estabilidad económica a escala mundial. Esta 'edad de oro' de la economía mundial comenzó a quebrarse, como es sabido, en la década de los 70, momento en que se produce la primera crisis del petróleo (1973), que provoca el aumento de la inflación y las tensiones sociales y cuyas secuelas en los países industrializados hacen que se ponga en tela de juicio el estado del bienestar y el compromiso con el pleno empleo.

\section{EL CONTEXTO POLÍTICO ESPAÑOL: DESARROLLO ECONÓMICO Y AUGE DE LA CONTESTACIÓN OBRERA}

En 1956, como consecuencia de haber ingresado poco antes en la ONU, España retornaba a la OIT, de la cual había formado parte desde el año mismo de su fundación, en 1919, y de la que había sido expulsada en $1941^{4}$. Si entre 1923 y 1937 este país había ratificado 27 convenios, entre 1956 y 1975 hará otro tanto con 63 , con objeto de conciliarse con la opinión mundial y contra-

4 MATEOS, 16 (1997a): 201-218; 1997b: 41. Como señala este autor, España había sido dada de baja en 1941 como consecuencia del aislamiento internacional del Régimen, aunque en ese momento se adujo desde la OIT el impago de cuotas. 
rrestar la labor de denuncia de las intersindicales. Eso sí, durante el largo periodo de la dictadura se resistirá a ratificar los convenios 87 y 98, anteriormente descritos, aduciendo la singularidad de la Organización Sindical Española (OSE) y aseverando que ésta, por sí misma, aseguraba la representatividad sindical y compaginaba la unidad con la libertad.

La labor de presión y denuncia de la UGT y la Confederación Internacional de Organizaciones Sindicales Libres (CIOSL) ante la OIT se produce en un contexto político marcado por los esfuerzos del régimen franquista de avanzar hacia su institucionalización, aprovechando el marco de la Guerra Fría, bajo la faz de la «democracia orgánica» ${ }^{5}$, y en un contexto económico de desarrollismo cuyo arranque suele situarse en 1959, momento en que se ponen en práctica los nuevos planes liberalizadores del equipo de gobierno ${ }^{6}$.

En el ámbito político, la leve apertura iniciada en este momento presentaba al régimen franquista como una «democracia orgánica» asentada sobre las tres entidades fundamentales de la vida social: «familia, municipio y sindicato». De esta forma, en 1958 fue promulgada la Ley de Principios del Movimiento Nacional que sustituyó a las envejecidas Leyes Fundamentales de los falangistas: dicha Ley pretendía ser una Constitución que sancionaba una Monarquía tradicional, católica, social y representativa, fiel a los inmutables principios del Dieciocho de Julio. Ese mismo año, y dentro del esfuerzo creciente por mejorar la imagen internacional del país, fue aprobada la Ley de Convenios Colectivos, cuyo cometido era avanzar en la representatividad de la Organización Sindical Española sin poner en peligro la filosofía originaria del sindicato vertical ${ }^{7}$.

5 SOTO CARMONA, 2005. MATEOS y SOTO, 2006. TOWNSON, 2009. PÉREZ LEDESMA y SAZ CAMPOS (Coords.), 2014. SAZ CAMPOS, 2007. GIMÉNEZ MARTÍNEZ, 2014.

6 GARCÍA DELGADO y JIMÉNEZ, 1999. GONZÁLEZ, 1979. MARTÍNEZ SERRANO, 1983. WRIGHT, 1980.

7 Frente a la fijación de las condiciones de trabajo por el ministerio del ramo, la nueva legislación establecía que dichas condiciones serían fruto de la negociación entre representantes de los empresarios y de los trabajadores en el marco de la OSE, lo cual permitía a los trabajadores concretar sus peticiones y presionar para obtenerlas. Sin embargo, como venía ocurriendo con las diferentes 'novedades' aperturistas del Régimen, la Ley contribuyó a incentivar y generalizar la conflictividad social: «Se puede afirmar que es cierto que la Ley de Convenios Colectivos resolvió problemas urgentes tanto del capitalismo español en general como del régimen franquista en particular, pero también que la instauración de la contratación colectiva fue beneficiosa para los trabajadores, porque aunque el nuevo ordenamiento jurídico no modificó el carácter de clase distinto del régimen franquista, sí que abrió una vía para la articulación de las reivindicaciones obreras. (...) La nueva ley evitó que el conflicto se produjera entre los trabajadores y el Estado, como sucedía en la etapa anterior a 1958, lo que les facilitó la consecución de sus reivindicaciones», MOLINERO e YSÁS, 1998: 64-65. LUDEVID, 1976: 36-40. SÁNCHEZ LÓPEZ y NICOLÁS MARÍN, 1993: 34. 
A la llamada «Ley Fraga» (Ley de Prensa) de 1966, que en alguna medida liberalizaba la política del régimen respecto a los medios de comunicación, vino a sumarse, en 1967, la Ley Orgánica del Estado que, además de introducir nuevos elementos institucionalizadores, llevó a cabo la función de coordinar todo el cuerpo de textos legales anteriores, depurándolo de algunas connotaciones totalitarias: por ejemplo, separaba los cargos de Jefe de Estado y Presidente de Gobierno, con delimitación específica de las funciones de ambos, abrió las Cortes a una cierta participación popular mediante la creación de la figura de los procuradores representantes de la familia, elegidos de forma directa por los cabezas de familia y las mujeres casadas, establecía la plena inserción de las fuerzas armadas dentro del sistema constitucional español como garantes de la integridad territorial, la seguridad nacional «y la defensa del orden institucional», y establecía la posibilidad de crear «asociaciones de acción política» como término medio entre el uniformismo y el pluripartidismo. Por fin, en 1969 se resolvió definitivamente la cuestión sucesoria, al proponer el Jefe de Estado a don Juan Carlos como sucesor a título de rey.

En el terreno propiamente económico, a partir de 1961, un crecimiento anual del $8,7 \%$ puso en evidencia el importante avance experimentado por la economía española: como media del decenio, el PIB creció un 7,5\% al año, se produjo una importante mejora financiera, técnica, comercial y productiva que aceleró la integración de la economía española en el capitalismo internacional, se incentivó el turismo, las remesas de emigrantes y la inversión extranjera, todo ello empujado por una buena coyuntura exterior, la estructura social se modernizó y ascendieron el nivel de vida, el consumo, la renta per cápita y las migraciones interiores y exteriores, con lo que se liberó la presión campesina.

Mas no todo fueron resultados positivos en este terreno: el «milagro» económico de los años 60 vino acompañado también de importantes desequilibrios regionales y sociales, la inflación se tornó aguda a finales de los 50, el campo quedó desatendido y las migraciones interiores produjeron graves problemas urbanísticos y de vivienda en los núcleos industriales. Asimismo, al hilo de la intensa modernización social experimentada y del surgimiento de una nueva clase media, también la oposición política y sindical se incrementó y experimentó una notable modernización a resultas de factores como nuevas aportaciones de militantes que no habían vivido la Guerra Civil ${ }^{8}$, influencias ideológicas de nuevo cuño y determinadas fórmulas, especialmente efectivas a partir de 1958, de movilización y acción socio-política que empleaban para ello los resortes legales existentes.

A este respecto, diversos autores han remarcado cómo en el periodo que va de 1962 hasta el final del Franquismo, las huelgas se generalizan y extienden a

\footnotetext{
8 MARAVALL, 1979.
} 
nuevos sectores productivos y zonas con escasa tradición de lucha obrera; igualmente, las demandas se centran en los contenidos de los Convenios y en la reivindicación de la libertad sindical, y las tácticas de la oposición favorecen la generalización de usos democráticos en los centros de trabajo y la incorporación de lo que se ha denominado «nueva clase obrera» ${ }^{9}$. Aunque el entonces secretario general del Movimiento, José Solís Ruiz, y sus sucesores trataron de aplicar una política de pequeñas reformas en el ámbito laboral y sindical que dieran más autenticidad al sindicato vertical franquista, el resultado fue un fracaso y las tácticas «entristas» empleadas por la oposición, en especial por Comisiones Obreras (CCOO), dieron buen resultado.

Eso último se vio reflejado en el éxito de las candidaturas opositoras en las elecciones sindicales de 1966, lo que llevó a los dirigentes del sindicato vertical a incrementar la vigilancia ante la contestación obrera y avanzar en la represión: en marzo de 1967, las CCOO fueron declaradas ilegales por el Tribunal Supremo, al tiempo que el estado de excepción de enero de 1969 servía para desarticular el emergente activismo sindical antifranquista. Un hito muy relevante en esta actividad represora fue el llamado «Proceso 1001», cuyo origen arranca con la detención, en junio de 1972, de diez activistas de CCCO y del Partido Comunista de España (PCE) que habían decidido reunirse en una residencia aneja al convento de Padres Oblatos de Pozuelo de Alarcón. El juicio se celebró los días 20 - fecha escogida por ETA para atentar contra el almirante Luis Carrero Blanco, presidente del Gobierno-, 21 y 22 de diciembre de 1973, y las penas se conocieron el 29. Las condenas oscilaron entre los 20 años y los 12 de reclusión menor, aunque en 1975 serían revisadas a la baja.

Pese a ello, la conflictividad obrera siguió creciendo ${ }^{10}$, pues los conflictos pasaron de 811 en 1973 a 1.119 al año siguiente. La respuesta de la dictadura consistió en el incremento de la violencia policial, lo que se tradujo en incidentes muy graves, con trabajadores heridos y muertos por disparos de la Policía Armada: en julio de 1970, tres obreros de la construcción de Granada en huelga murieron por disparos policiales; y en octubre del año siguiente, una protesta en la factoría SEAT de Barcelona se saldó con una batalla campal cuando las fuerzas policiales trataron de dispersar a los trabajadores concentrados, con el resultado de un manifestante muerto y varios heridos.

Pocos meses después, los días 9 y 10 de marzo de 1972, la policía actuó de igual manera ante una nueva protesta laboral, esta vez en la Empresa Nacional Bazán, de El Ferrol, acabando con la vida de dos trabajadores. En toda España se sucedieron protestas contra la actitud de la policía, pues lo sucedido en El

9 SOTO CARMONA, 30 (1998): 39-63. MOLINERO e YSÁS, 1998. BABIANO MORA, 1995. DOMENECH, 2008. FISHMAN, 1990. RUIZ, 1993. BALFOUR, 1994. BENITO DEL POZO, 1993. SOTO CARMONA, 1994.

10 YSÀS, 3 (2007). 
Ferrol se sumaba a la también violenta actuación de las fuerzas de orden público en Vitoria, a raíz de una huelga en la empresa Safen Michelin, violentamente dispersada por la policía. El 3 de abril de 1973, trabajadores de las empresas constructoras de una central térmica en Sant Adrià de Besós se concentraron a las puertas de la obra en huelga por sus condiciones laborales: el duro enfrentamiento con la policía se cobró una nueva vida. No es casualidad, por tanto, que las elecciones sindicales de junio de 1975 dieran como resultado el triunfo de las llamadas «candidaturas democráticas y unitarias», propiciadas por CCOO y otros sindicatos no legalizados como la Unión Sindical Obrera (USO).

\section{LA UGT Y EL GRUPO DE ESTUDIO DE LA OIT. UN INFORME PARA LA PRO- TESTA}

Como señala Manuela Aroca, el estudio de la dimensión internacional de la UGT durante el Franquismo se revela fundamental para entender la supervivencia del sindicato socialista durante el largo periodo de la dictadura, así como su capacidad para compensar en el exterior su «ausencia» en la acción sindical interna ${ }^{11}$. Además, tampoco se puede explicar la reconstrucción de la UGT en el tardofranquismo sin reparar en la ayuda prestada por organismos internacionales como la OIT, pero más aún sin tener presente el apoyo material, moral y económico prestado por la CIOSL, así como su pertenencia a la Confederación Europea de Sindicatos desde su fundación en 1973.

Hasta 1976, fecha de la celebración del histórico XXX Congreso del sindicato, sus dirigentes del exilio explotaron con éxito su estrecha vinculación con el mundo de la CIOSL y el europeísmo, fomentaron las denuncias de la intersindical en el seno de la OIT en relación a la ausencia de libertad sindical en España y a la represión del régimen de Franco hacia los trabajadores que se manifestaban de diferentes maneras contra el sindicalismo oficial, y fueron preparando los apoyos internacionales para consolidar la UGT tras la dictadura.

Está bien documentado el apoyo material, moral y económico de la CIOSL al sindicato socialista ${ }^{12}$. Así actuó a través de su Comité de Solidaridad con España, al tiempo que presionaba contra el régimen denunciando el estado de excepción, la falta de libertades y la represión por medio del Comité de Libertad Sindical (CLS) de la OIT ${ }^{13}$. Amparada por la CIOSL, la UGT presionará

11 AROCA MOHEDANO, 2011; 2014: 15-52.

12 Junto a los trabajos de Aroca citados más arriba, ver MATEOS, 2008, 103-155; 2001: 133-198. También, ORTUÑO, 2005: 67 y ss.

13 En 1951, el Consejo de Administración la OIT creó la Comisión de Investigación y Conciliación y el Comité de Libertad Sindical, para examinar las quejas de violaciones de este principio. 
en la doble dirección de denunciar la incompatibilidad del sindicato vertical (OSE) con los principios de la OIT, pero también la del propio régimen franquista con la Declaración de Filadelfia, al tiempo que trataba de obtener visibilidad mediante la denuncia constante de la represión hacia la oposición sindical. Unas denuncias que la CIOSL y la Confederación Internacional de Sindicatos Cristianos (CISC) incentivaron más si cabe a raíz de las huelgas de 1962 y 1963.

Con todo, hasta 1968, una serie de circunstancias pusieron a la UGT y a sus máximos dirigentes en el exilio, en especial a Pascual Tomás, en situación de alerta ${ }^{14}$. En primer lugar, la labor de José Solís al frente de Sindicatos, en el sentido de propiciar una mínima y calculada apertura que otorgara legitimidad a la OSE en el plano internacional, especialmente en el seno de la OIT $^{15}$. Así se pudo comprobar con ocasión de la visita a España, en diciembre de 1965, de su director general, David Morse, realizada en un tono más que conciliador; y ello explica, por otro lado, que al año siguiente, la UGT frustrara la propuesta lanzada por José Solís a la CIOSL para que una delegación visitara nuestro país y analizara el sistema sindical.

Precisamente en la CIOSL se fue abriendo una postura respecto de España, impulsada fundamentalmente por los socios norteamericanos, partidaria de aprovechar las oportunidades que para la apertura sindical pudiera propiciar el desarrollo económico del país, pero también para hacer frente al posible avance del comunismo en el terreno sindical - explicitado en la labor del PCE a través de $\mathrm{CCOO}-$, mediante la fusión de organismos que pudieran ser competencia en el terreno socialista o socialdemócrata, instando sobre todo a la acción en el seno de las empresas españolas.

Es en este contexto de dedicación ugetista a la esfera internacional como herramienta de lucha contra el Régimen en el que acontece el famoso informe del Grupo de Estudio de la OIT. Para comprenderlo en toda su dimensión conviene recordar cómo a partir de diciembre de 1966, el régimen franquista recrudece la represión contra el movimiento obrero, sobre todo a raíz de los acontecimientos huelguísticos que se suceden en regiones como Asturias y País Vasco, y en ciudades como Barcelona y Madrid. El clima de tensión política y agitación laboral, unido a la creciente conflictividad universitaria, justificó la declaración del estado de excepción el 24 de enero de 1969, durante tres meses. En este contexto se produjo la visita a España del Grupo de Estudio de la OIT ${ }^{16}$, iniciativa aprobada en el Consejo de Administración de junio

14 Las obras fundamentales para las relaciones entre la España franquista y la OIT siguen siendo las de MATEOS, 1997a y MARTÍNEZ QUINTEIRO, 1997.

15 MATEOS, 8 (1995): 295-329.

16 Comunicados de Prensa de la OIT, 31 de mayo de 1968 y 15 de octubre de 1968, IIHS, carpeta 381-09. 
de 1968 a raíz de la invitación del gobierno español y la constante presión que se hacía desde las intersindicales, sobre todo desde la CIOSL, denunciando la represión franquista contra la clase obrera comprometida con el sindicalismo libre. El Grupo se estructuró en octubre y su objetivo era examinar la situación social y laboral de España para comprobar en qué medida se cumplían o infringían los principios de la OIT que obligaban a todos los miembros de la misma. Debido al estado de excepción, el Grupo de Estudio hubo de retrasar su llegada a España hasta el 7 de marzo de 1969. Presidido por Paul Ruegger ${ }^{17}$, hasta el día 30 sus componentes visitaron varias ciudades españolas (Madrid, Barcelona, Bilbao, Oviedo, Gijón, Avilés, Sama de Langreo, Toledo, Valencia, Sevilla, Badajoz, Zaragoza, La Coruña, Burgos y Valladolid) y se entrevistaron con ministros, subsecretarios, miembros de la OSE y de la oposición; entre estos últimos, los militantes del Partido Socialista Obrero Español (PSOE) y UGT Ramón Rubial, Enrique Múgica, Julio Escandell, Enrique Alonso Iglesias, Eduardo López Albizu, Manuel Martín Rueda, Manuel Martín Díaz y Miguel Peydró.

El informe provisional de la visita, hecho público en abril, reconocía la mayor representatividad y autonomía de la OSE, tal como buscaban las autoridades sindicales españolas, sobre todo el propio Solís, empeñado en sacar adelante la reforma de la Ley Sindical anunciada en el Congreso de Sindicatos de Tarragona, en mayo de 1968. Aunque el texto también criticaba la falta de libertad y la represión ejercida contra sindicalistas por acciones que en otros países eran consideradas legítimas, la CIOSL lo acogió con evidente desagrado: en un comunicado fechado el 16 de mayo de $1969^{18}$, criticó el hecho de que el Informe no desvelara toda la represión contra sindicalistas y la falta de libertad sindical. Por su parte, la UGT se pronunció desde el exilio a través de dos declaraciones, el 25 de mayo y el 6 de junio de $1969^{19}$. En ellas, aparte de trazar la historia de la OSE, rechazaba el contenido de la reforma de la Ley Sindical y lamentaba que los miembros del equipo de estudio hubieran restado importancia a las actividades de la oposición. La Comisión Ejecutiva del sindicato reprodujo sus alegatos en El Socialista, cuyo número

17 A propuesta del director general de la Oficina Internacional del Trabajo, la Mesa Directiva del Consejo de Administración decidió el 14 de octubre de 1968 que el Grupo de Estudio estuviese presidido por Paul Ruegger, miembro de la Corte Permanente de Arbitraje, del Instituto de Derecho Internacional, y de la Comisión de Expertos en Aplicación de Convenios y Recomendaciones de la OIT, a quien acompañaban Julio Augusto Barboza-Carneiro, ex presidente del Consejo de Administración de la OIT, y Pier Pasquale Spinelli, ex director general de la Oficina de las Naciones Unidas en Ginebra, Comunicado de Prensa de la OIT, 15 de octubre de 1968, IIHS, carpeta 381-09.

18 Comunicado de la CIOSL, 16 de mayo de 1969, IIHS, carpeta 381-09.

19 Valoración de la Comisión Ejecutiva de la UGT del informe del Grupo de Estudios enviada al director general de la OIT, Toulouse, 6 de junio de 1969, IIHS, carpeta 381-09. 
del 5 de junio de 1969 lo dedicó casi íntegro — portada y seis páginas—, a un Informe provisional que consideraba excesivamente «equilibrado» y asombrosamente mesurado a la hora de abordar las causas del estado de excepción y la represión contra los sindicalistas:

No estará de más que ahora digamos nuestra extrañeza al ver que al tratar las causas que determinaron la implantación del «estado de excepción», que ha servido para desatar la cruel represión contra la oposición democrática, que se cebó muy especialmente contra la clase trabajadora y que todo el mundo condenó, el Grupo de Estudio se limite a reproducir la tesis del gobierno que figura en el Preámbulo del Decreto Ley, es decir, la efervescencia universitaria, cuando nadie ignora que eso no fue más que el pretexto.

Nuestra extrañeza no ha sido menor en lo que se refiere a los malos tratos que han sufrido las víctimas de la represión; el informe se limita a recoger las engoladas declaraciones del ministro de Justicia y del Fiscal del Tribunal Supremo, que niegan que en las cárceles se maltrate a los presos; que la ley prohíbe y hasta castiga al funcionario que se entregue a ese menester y que si se denunciara en debida forma la existencia de algún caso, se seguiría el consiguiente proceso. El Grupo de Estudios sabe, debería saber, que es en las comisarías de policía y en los cuartelillos de la Guardia Civil donde se apalea brutalmente y se aplican tormentos a los detenidos durante los inhumanos interrogatorios a que se les somete ${ }^{20}$.

De igual manera, no entendía este sindicato la condescendiente manera que tenía el informe de tratar el pasado y presente de la estructura sindical vertical, ni la elusión de todo lo concerniente al derecho de huelga. Solo le satisfacía la mención que hacía de los movimientos sindicales clandestinos y del deseo de la mayor parte de la opinión española de ver implantado un sindicato auténticamente obrero y representativo, así como las recomendaciones para que la Ley Sindical en ciernes se ajustara a los principios de la OIT.

El Informe definitivo, fechado el 31 de julio de 1969, insistía en recordar la ausencia de libertad sindical en España y denunciar la represión contra quienes pugnaban por un sindicalismo democrático, y se refería a la proyectada reforma de la Ley Sindical señalando la contradicción existente entre la legislación sindical española y las normas de la OIT, por lo que establecía cinco condiciones para superar dicha divergencia: todos los puestos de trabajo debían ser cubiertos por elección, debía existir una completa autonomía para los sindicatos, los sindicalistas elegidos debían tener poder sobre los representantes designados y sobre asuntos financieros y administrativos, ningún movimiento político debería dirigir o controlar el entramado sindical, y habría de garantizarse la libertad de expresión y de reunión.

20 «La Oficina Internacional del Trabajo, el gobierno franquista y la verdadera situación de los trabajadores en España», El Socialista, 381, 5 de junio de 1969: 1. 
A juicio de Abdón Mateos, «las conclusiones en esta misión internacional, aunque reconocía ciertos cambios en la legislación sociolaboral y evolución de la OSE, constituyeron una derrota para la dictadura pues se expresaba claramente la ausencia de libertades sindicales ${ }^{21}$. Así lo interpretó la CIOSL a través de un comunicado en el que remarcaba todo lo que de crítica y denuncia del sindicalismo oficial español se derivaba del Informe 22 . Para Harm Buiter, su secretario general, el documento venía a confirmar «que en España la libertad de asociación, las libertades civiles, los derechos sindicales y el derecho de huelga no existen», que la OSE no era una organización verdaderamente independiente y representativa, que su poder ejecutivo estaba en manos de dirigentes nombrados por el gobierno, que la afiliación era obligatoria para trabajadores y empresarios y que los delegados sindicales que osaban defender los derechos de los trabajadores eran expulsados.

La CIOSL hacía mención expresa de los sindicatos UGT y Solidaridad de Trabajadores Vascos (STV), abocados a operar en la clandestinidad, y recalcaba que «actividades sindicales consideradas como normales en otros países son objeto de severas penas legales en España». Las huelgas, además, seguían siendo ilegales, de modo que sus impulsores «son detenidos, torturados en las comisarías de policía, sentenciados a largas penas de prisión y multados. Los huelguistas son despedidos». En consecuencia, la CIOSL volvía a reiterar su demanda de cambios profundos en la legislación española y en la práctica sindical antes de que se pudiera considerar que el sistema español seguía las normas y principios de la OIT, así como una reforma de la legislación penal y una amnistía o indulto para sindicalistas detenidos.

El Informe se debatió en el Consejo de Administración de la OIT de noviembre, y el Grupo de Trabajadores lo empleó para insistir en aquellas conclusiones que refrendaban la apuesta por un sindicalismo libre y democrático con plenas garantías. Asimismo, lamentaba que el proyecto de reforma de la ley sindical que preparaba el gobierno no estuviera basado en las sugerencias y recomendaciones del grupo de estudio, y que no se hiciera caso a su propuesta de declarar una amnistía general a favor de los trabajadores encarcelados. Por todo ello terminaba solicitando al Consejo de Administración que hiciera lo necesario para que los órganos apropiados de la OIT estuvieran constantemente al corriente de la situación laboral y sindical en España, a fin de asegurar el adecuado cumplimiento de las propuestas del grupo de estudio.

Especialmente relevante para los intereses de la UGT fue la postura adoptada por la CIOSL en el Comité Ejecutivo de marzo de $1970^{23}$, pues además de recalcar lo ya expuesto en el Consejo de Administración en cuanto a que

21 MATEOS, 2 (1989): 346.

22 Comunicado de Prensa de la CIOSL, 18 de septiembre de 1969, IIHS, carpeta 380-04.

23 Comité Ejecutivo de la CIOSL, Bruselas, 11 y 12 de marzo de 1970, IIHS, carpeta 163. 
se «adoptasen todas las medidas adecuadas para mantener bajo revisión permanente la situación laboral y sindical de España», aseguraba que «estamos determinados a mantener el problema de los derechos sindicales y las libertades en España ante la OIT hasta que se restauren plenamente los derechos humanos y sindicales fundamentales». En efecto, como luego veremos con más detenimiento, la CIOSL, amparándose en el contenido del informe definitivo del grupo de estudio, incentivará sus denuncias ante la OIT sobre la situación social y sindical de España, haciendo especial hincapié en la represión contra aquellos trabajadores que luchaban en pro de un sindicalismo libre, democrático y verdaderamente representativo, o que reivindicaban una serie de mejoras laborales a través de actividades que en otros países eran consideradas legales, tales como la huelga o la difusión de propaganda ${ }^{24}$.

$\mathrm{Y}$ es que, pese a sus limitaciones, el texto proporcionó importantes argumentos a los grupos de la oposición sindical, y a los ugetistas en particular. Ya es significativo, por ejemplo, que durante la discusión del informe interino en la 53 Conferencia de la OIT, los delegados de los trabajadores pertenecientes a organizaciones afiliadas a la CIOSL en la República Federal Alemana, Austria, el Reino Unido, Bélgica, Francia Noruega y Dinamarca consiguiesen sacar adelante una resolución sobre España que denunciaba la represión sobre numerosos líderes sindicales a pesar de la amnistía solicitada ${ }^{25}$. Sin embargo, también es cierto que las esperanzas depositadas en el texto, sobre todo a la hora de consensuar una resolución contra el sistema sindical español, se toparon muy pronto con las limitaciones inherentes al complejo mecanismo de funcionamiento y representación tripartita de la OIT. Así ocurrió en junio de 1970, cuando el grupo de trabajadores de la 54 Conferencia Internacional, a través de sus delegados de Austria (Anton Benya), Gran Bretaña (Cyril Plant), República Federal Alemana (Gerd Mühr) y Suecia (Thorbjörn Carlson), trató de sacar adelante una resolución condenatoria contra el sindicalismo oficial español por no ser representativo, al tiempo que denunciaba la represión ejercida contra los trabajadores que demandaban mejores condiciones laborales, así como la negativa del gobierno a ratificar los convenios 87 y 98 . En concreto, la resolución, que fundía los textos redactados separadamente por la CIOSL, la Federación Sindical Mundial (FSM) y la Confederación Mundial del Trabajo (CMT), pretendía que el gobierno español cumpliera las recomendaciones contenidas en el informe del grupo de estudio adaptando la

24 Por ejemplo, el 15 de octubre de 1969, Morris Paladino, secretario general adjunto de la CIOSL, escribía a Manuel Muiño solicitando información sobre la detención de 19 compañeros de la UGT para enviar una queja al Comité de Libertad Sindical de la OIT, vinculado al informe del grupo de estudio, Morris Paladino a M. Muiño, 15 de octubre de 1969, IIHS, carpeta 315 a.

25 MARTÍNEZ QUINTEIRO, 1997: 99 y ss. ORTUÑO, 2005: 84-85. 
legislación a las normas de la OIT, retirando el proyecto de Ley Sindical, aprobando una amnistía generosa para los encarcelados por actividades sindicales que en otros países eran legítimas, reformando el Código Penal y aboliendo el Tribunal de Orden Público:

Los trabajadores españoles siguen privados del derecho a constituir organizaciones sindicales y a afiliarse a las mismas con arreglo a los principios y a la práctica del Convenio sobre la libertad sindical y a la protección del derecho de sindicación. (...). El Gobierno español no solo no adapta la legislación de España a los principios y normas de la OIT, sino que ha sometido a las Cortes un proyecto de Ley Sindical elaborado sin discusión libre y democrática por parte de los trabajadores, al tiempo que somete a estos a medidas represivas, detención, encarcelamiento y persecución. (...)

[Que la conferencia general de la Organización Internacional del Trabajo] pida al gobierno español, con vistas a la restauración del sindicalismo libre y democrático y del pleno respeto de las libertades civiles en España, retire el proyecto de Ley Sindical y adopte medidas inmediatas para atenerse a las numerosas recomendaciones del Comité de Libertad Sindical y a las observaciones y recomendaciones del informe final del grupo de estudio (...) en favor de una generosa amnistía o indulto en favor de las personas encarceladas por actividades que en otros países serían consideradas como legítimas actividades sindicales ${ }^{26}$.

Aunque apoyada por todos los delegados de los trabajadores excepto por el español Noel Zapico, finalmente la resolución no salió adelante en la Comisión por un estrecho margen de votos: 10.486 en contra, 9.754 a favor y 1.870 abstenciones. Lo más doloroso para los impulsores de la iniciativa fue ver cómo se abstenían los representantes gubernamentales de países con presencia socialista en sus gobiernos, como la República Federal Alemana, Austria, Bélgica, Holanda y Gran Bretaña ${ }^{27}$. Como informaba Morris Paladino, secretario general adjunto de la CIOSL, a Manuel Muiño,

26 Se invitaba al Consejo de la OIT a proceder a una revisión constante de la situación laboral y sindical de España, a informar periódicamente sobre los acontecimientos relacionados con los derechos y libertades en España, y a someter a la 55 Conferencia Internacional del Trabajo un informe sobre los resultados obtenidos por la OIT en pro de la restauración de la libertad sindical en España: El Socialista, 434, 25 de junio de 1970: 5. Información Española, 43 (1 de julio de 1970): 4.

27 Votaron a favor los representantes gubernamentales de Italia, Suecia, Dinamarca y Noruega. El grupo de empleadores votó en contra, salvo Checoslovaquia y Polonia. Servicio de prensa de IG Metall, 320 (1 de julio de 1970): 1-2, FAGFITEL, Hemeroteca. También en MARTÍNEZ QUINTEIRO, 1997: 205 y ss. Como recordaba Manuel Simón Velasco, «lo que más dolió, además, es de comprobar [sic], de constatar que faltaron muchos votos de gobiernos precisamente amigos, europeos. Incluso, gobiernos en los que gobernaban los socialistas o los laboristas», Entrevista a Manuel Simón Velasco realizada por Manuela Aroca Mohedano, Madrid, 10 y 16 de noviembre, 7, 9 y 10 de diciembre de 2010, FFLC, 004209-001. 
La abstención del bloque de los países del Mercado Común y de la Gran Bretaña fueron fatales instrumentos en la votación (...). En Europa solamente los Países Escandinavos e Italia fueron los únicos gobiernos democráticos a favor de la resolución. Esto ha creado el natural descontento e incluso la indignación de los compañeros sindicalistas de diversos países ${ }^{28}$.

Tampoco la ejecutiva de la UGT dejó pasar la oportunidad de afear tamaño proceder:

Tan ponderada, razonada y digna propuesta parecía llamada a obtener si no una aprobación general sí una aprobación substancial (sic). Ello no fue así por la abstención incomprensible e injustificable de los representantes gubernamentales de los países que, principalmente en Europa, blasonan de encarnar y ser custodios de la democracia y de la libertad ${ }^{29}$.

A lo más que se llegó fue a la aprobación de una resolución genérica que, aun sin citar a España, en realidad la afectaba de lleno, pues recordaba que el concepto de derechos sindicales «carece totalmente de sentido cuando no existen las libertades civiles», expresaba la «profunda inquietud» de la Conferencia «por las violaciones repetidas de los derechos sindicales», insistía en la necesidad de ratificar los convenios 87 y 98, e invitaba a reforzar los mecanismos dirigidos a observar los principios de la OIT relativos a la libertad sindical y a los derechos sindicales.

\section{LA OIT, INSTRUMENTO DE PRESIÓN Y DENUNCIA}

Desde el mismo año de la entrada de España en la OIT se sucedieron las quejas de las organizaciones sindicales internacionales, especialmente de la CIOSL, acerca del carácter autoritario del sistema político, la ausencia de libertad sindical y la falta de representatividad de los delegados de los trabajadores españoles de acuerdo con el artículo 3 de la Constitución de la OIT ${ }^{30}$.

28 Carta de M. Paladino a Muiño, 22 de junio de 1970, IIHS, carpeta 3015. También Comité Ejecutivo de la CIOSL, Bruselas, 8 a 10 de diciembre de 1970, IIHS, carpeta 3015.

29 El Socialista, 442, 20 de agosto de 1970: 2. De igual manera, en la memoria redactada con ocasión del XI Congreso del sindicato socialista (1971) se aludía a lo sucedido en la 54 Conferencia de la OIT señalando que dicha resolución recogía «el espíritu de las quejas que había venido presentado [la CIOSL] en la OIT contra el régimen franquista» y que si su aprobación no fue posible se debió, fundamentalmente, a «la conducta incalificable de algunos delegados gubernamentales de países democráticos con participación socialista absteniéndose en la comisión de resoluciones», Memoria presentada al XI Congreso (1971), FFLC, caja 3-030: 57 y ss.

30 Desde 1956, la Comisión de verificación de poderes acogió impugnaciones contra la representación sindical española, que no prosperaron. Otras referencias negativas a la situa- 
De igual manera, en la etapa que nos ocupa, la UGT, sobre todo a raíz del informe definitivo emitido por el grupo de estudio sobre la situación social y sindical de España, se servirá de su presencia en la CIOSL para seguir presionando en la OIT en un triple sentido: la ausencia de libertad y pluralidad sindical en España (el régimen de Franco, como ya hemos señalado, se negaba a ratificar los Convenios 87 y 98), la falta de representatividad de la anunciada nueva Ley Sindical y la represión contra el movimiento obrero ${ }^{31}$. Para ilustrar esto último, la CIOSL se basará en casos concretos de persecución franquista contra militantes de base y líderes ugetistas ${ }^{32}$. Ya en diciembre de 1968, la UGT anunció una jornada de lucha para el 31 de enero de 1969, que organizaría el Comité Central socialista y la UGT de Euskadi. Esta jornada tuvo un éxito relativo en la ría de Bilbao, donde en diciembre de 1968 ya habían caído hasta 39 militantes en una redada ${ }^{33}$. En varias ocasiones, la CIOSL formulará la pertinente queja ante el director general de la OIT, solicitando de paso su intervención para lograr la liberación de los ugetistas detenidos ${ }^{34}$.

Asimismo, el 24 de enero de 1969, en el marco del estado de excepción, fueron detenidos en Vizcaya algo más de 60 militantes socialistas, siendo ésta

ción sindical de España se sucedieron en varios trabajos de la Comisión de la Conferencia en aplicación de convenios y recomendaciones, tomando como base informes de la Comisión de Expertos, como ocurrió en 1973. De igual manera, la memoria del director general de la OIT, David Morse, presentada a la 52 reunión de la Conferencia, en 1968, y titulada La OIT y los Derechos Humanos, contenía referencias desfavorables a España: «Ley 19/1977, de 1 de abril, sobre regulación del derecho de asociación sindical y la ratificación por España de los convenios núms. 87 y 98 de la Organización Internacional del Trabajo»: VILLÁN DURÁN, 114 (1977): 98.

31 Como recordaba Manuel Simón Velasco, vocal de la Comisión Ejecutiva de la UGT, la OIT era para ella un altavoz privilegiado para sus demandas, «una plataforma, una atalaya universal, mundial», Entrevista a Manuel Simón Velasco realizada por Manuela Aroca Mohedano, Madrid, 10 y 16 de noviembre, 7, 9 y 10 de diciembre de 2010, FFLC, 004209-001.

32 A este respecto, no podemos pasar por alto la confluencia entre la mayor participación de la UGT en la conflictividad obrera de finales de los años sesenta con el propio proceso de reestructuración interna del sindicato, expresada ésta en el paulatino predominio, en los órganos directivos, de los militantes del interior sobre los líderes históricos del exilio: MATEOS, 2001: 122 y ss. Como es bien sabido, ya en el Congreso de la UGT de 1970, aun manteniendo la dirección compartida, se apuntó la necesidad de establecerla en la Península. Al año siguiente, el histórico XI Congreso, celebrado en Toulouse los días 5 y 6 de agosto, aprobó la colaboración con todas las fuerzas antifranquistas — incluido el PCE—, y la proposición de las federaciones del interior de devolver el ejecutivo a la organización clandestina mediante una dirección colegiada con expresa supresión del cargo de secretario general. Así se hizo: aquel Congreso, histórico, dispuso que la dirección pasara a estar mayoritariamente en el interior, creándose una ejecutiva colegiada con nueve miembros residentes en España y sólo cinco en el exilio: Acta de la Comisión Ejecutiva de UGT, 9 de mayo de 1971, FFLC, caja 432. MARTÍNEZ COBO y MARTÍNEZ COBO, 1990: 599-60.

33 MATEOS, 1997: 151-152

34 El Socialista, 359, 2 de enero de 1969: 4. 
la última caída general y masiva de ámbito regional del PSOE y la UGT durante la dictadura. Al mes siguiente la CIOSL enviaba la pertinente denuncia al director general de la OIT, David Morse, haciendo mención expresa de las detenciones y sentencias contra ugetistas como Santiago Tapia Hernando, Juan José Berrocal, Adolfo Jiménez Garaygordobil, José Luis Echa, Eduardo López Albizu, Gregorio Illoro Ruiz, Nicolás Martínez Esturo, Arturo Agüero Piaño e Ignacio Merino, todos en prisión provisional ${ }^{35}$. Dos meses después, aprovechando la reciente visita del grupo de estudio, así como la publicación de sus conclusiones provisionales, el secretario general de la CIOLS denunció en la Confederación Internacional del Trabajo la vulneración de los derechos, volviendo a insistir en el hecho de que fueran consideradas ilegales unas actividades sindicales que en otros países eran consideradas legítimas ${ }^{36}$.

A finales de octubre, los juicios celebrados contra 22 sindicalistas vascos pertenecientes a la UGT, condenados a diversas penas de prisión por «asociación ilegal», y contra otros acusados de haber organizado secciones del sindicato en Vizcaya, establecer comités de fábrica elegidos democráticamente, recaudar cuotas de afiliación y haber asistido a cursos de formación sindical en Suecia y Francia patrocinados por organizaciones afiliadas a la CIOSL, sirvieron nuevamente para formular la pertinente denuncia ante la OIT $^{37}$. Las alegaciones del gobierno español para demostrar que los detenidos, juzgados y sentenciados no lo eran por motivos sindicales sino de orden público se basaban en que la UGT había sido declarada ilegal en España. Este hecho era inadmisible para el Comité de Libertad Sindical, como lo demuestra la respuesta dada a este caso concreto («caso 612»):

A este respecto, el Comité debe señalar nuevamente, como ya lo ha hecho en el pasado, que una situación conforme a la cual no se admiten las organizaciones profesionales de trabajadores establecidas al margen de la organización sindical reconocida por la ley, está en contradicción con el principio de que los trabajadores tienen el derecho de constituir, sin autorización previa, las organizaciones que estimen convenientes. Asimismo, la aplicación de sanciones a los trabajadores por el hecho de ser de una de estas organizaciones es contraria al principio de libre afiliación de los trabajadores.

Los rescoldos represivos de 1969 y las condenas contra militantes socialistas de Sevilla tuvieron también su reflejo en el Comité de Libertad Sindical de la OIT de 16 de febrero de 1970, cuyo 116 Informe se centraba en los casos

35 Denuncia de la CIOLS al director general de la OIT, 11 de abril de 1969, IIHS, carpeta 381-09.

36 El Socialista, 385, 3 de julio de 1969: 2.

37 La denuncia está fechada el 27 de octubre de 1969: Comité Ejecutivo de la CIOSL, Bruselas, 11 y 12 de marzo de 1970, IIHS, carpeta 163. 
denunciados a la CIOSL y CMT por UGT, CCOO, USO y STV sobre la represión contra líderes sindicales de primera fila. Entre ellos sobresalía la condena a Evaristo Martínez, de UGT, diversas detenciones por repartir folletos a favor de la abstención en las elecciones sindicales de 1966, y las medidas adoptadas contra militantes muy relevantes en el sindicato, como Ramón Rubial, en Vizcaya, durante el estado de excepción de 1969. También se recordó el arresto, por asociación ilícita, en julio de 1968, de Nicolás Redondo y Eduardo López Albizu, así como otras detenciones de ugetistas en 1968 y 1969.

Más adelante, en agosto de 1970, la CIOSL esgrimía el informe del grupo de estudio para protestar ante el embajador de España en Londres por los sucesos ocurridos en Granada y solicitar al gobierno «que elimine los obstáculos que impiden el ejercicio independiente de los derechos sindicales de los trabajadores españoles ${ }^{38}{ }^{3}$. Especial incidencia tuvo la detención, el 31 de enero de 1971, de personas de gran relevancia en el PSOE y la UGT del interior, como Felipe González, Enrique Múgica, Nicolás Redondo, Cristóbal Cáliz y Ambrosio Gutiérrez, a quienes se requisó material de propaganda y otros documentos relacionados con la UGT y el PSOE. Sobre este asunto la CIOSL dirigió una amplia queja al director general de la OIT, Wilfred Jenks, instándole a presentar el caso (sería el 658) en el Comité de Libertad Sindical39. Éste solicitó la pertinente información al Gobierno, que en octubre respondió señalando que las personas detenidas lo habían sido «por promover grupos subversivos para atentar contra la seguridad del Estado, ocupándoseles material de propaganda incitadora a la violencia», pero que todos los inculpados ya se encontraban en libertad ${ }^{40}$.

Mención aparte merece la reforma de la Ley Sindical, que, tras una compleja tramitación que incluyó un duro enfrentamiento entre José Solís y el vicepresidente Carrero Blanco ${ }^{41}$, en el que el primero trató de utilizar a la OIT como principal refrendo internacional, se aprobó en las Cortes el 16 de febrero de 1971. Ya en octubre de 1969, al conocerse públicamente el proyecto, la UGT lo consideró una «estafa infinitamente mayor y de más graves conse-

38 CIOSL al embajador de España en Londres, 3 de agosto de 1970, IIHS, carpeta 3015.

39 Notificación del secretario general de la CIOSL a W. Jenks, 15 de febrero de 1971, IIHS, carpeta 3015. En la queja se detallaba que los cinco detenidos habían sido acusados de delito de asociación ilegal y propaganda ilícita. Fueron puestos en libertad provisional mediante fianza de 50.000 pesetas, en el caso de Gutiérrez, y de 30.000 en el resto, El Socialista, 470, 18 de marzo de 1971: 8 .

40 En «Voces por la libertad sindical», Educación Obrera, 112 (1998/3): 38-39.

41 En el Congreso de la OSE de Tarragona se defendió la plena representatividad de los cargos de la Organización Sindical, hasta la presidencia, la separación de la OSE del Movimiento, la desaparición de la fórmula «Sindicato Vertical» y la eliminación de la terminología nacional-sindicalista, MATEOS, 1997: 122 y ss. SOTO CARMONA, 8 (1995): 251 y ss. SÁNCHEZ LÓPEZ y NICOLÁS MARÍN, 1993: 146. LUDEVID, 1976. 
cuencias que las de Matesa», y denunciaba que, pese a la fraseología empleada, seguía siendo un proyecto de corte totalitario que no cumplía ni una sola de las recomendaciones del grupo de estudio de la OIT ${ }^{42}$. De igual manera, la «Nota sobre el proyecto revisado de Ley Sindical» enviada por la CIOSL al director de la OIT lo invalidaba por completo:

No es sino una simple reforma de la estructura de la organización sindical oficial (...). Ninguna de las cinco condiciones sugeridas por el grupo de estudio de la OIT han sido tomadas en consideración por el gobierno español (...). Ni tal legislación está de acuerdo con los principios y normas de la OIT43.

La CIOSL reproducía asimismo los graves reparos al proyecto de Ley que venía difundiendo el sindicato socialista, en especial la ausencia de autenticidad obrera del sindicalismo oficial español, el mantenimiento de la línea política de mando y la dependencia respecto del Estado, la ausencia de regulación, por parte del sindicato, de los convenios colectivos, el no reconocimiento del derecho a la huelga, el mantenimiento de una legislación penal que castigaba actividades sindicales que eran legítimas en otros países, y el hecho de que siguiera en vigor la legislación que en 1939 disolvía las organizaciones sindicales libres y democráticas.

Nada cambiaría a partir del 16 de febrero de 1971, una vez aprobada la Ley Sindical por las Cortes franquistas. Para la UGT, aunque la disposición decía reconocer el principio de la representatividad y que todos los representantes sindicales serían elegidos por los sindicados, en realidad era una «farsa» por mantener la línea política de mando y yugular toda independencia sindical ${ }^{44}$. La campaña internacional no se haría esperar: al día siguiente de la aprobación de la Ley, Harm G.Buiter, secretario general de la CIOSL, haciéndose eco de lo acordado entre esta organización, la Comisión Ejecutiva de la UGT ${ }^{45}$ y la Confederación de Sindicatos Alemanes, la condenaba públicamente al no ver en ella más «que la prosecución del actual sistema represivo» ${ }^{46}$, limitarse únicamente a acometer «una simple reforma de la estructura interna de los sindicatos de Estado», y mantener la línea política de mando, la afiliación obligatoria y la prohibición del derecho a la huelga; en definitiva, todo lo contrario a lo contenido en las normas y recomendaciones de la OIT, en particular del grupo de estudio:

42 El Socialista, 397, 9 de octubre de 1969: 1; y 398, 16 de octubre de 1969: 1 y 2.

43 Nota sobre el proyecto revisado de Ley Sindical, IIHS, carpeta 3015.

44 «En el reino de la farsa. La nueva Ley Sindical», El Socialista, 467, 25 de febrero de 1971: 1 .

45 Declaración de la Comisión Ejecutiva de la UGT, 21 de febrero de 1971, El Socialista, número especial, febrero de 1971: 4; 468, 4 de marzo de 1971: 1.

46 Declaraciones reproducidas en El Socialista, 469 (11 de marzo de 1971): 1. 
Un ministro designado por el general Franco conserva la dirección de la organización sindical oficial de la que, como anteriormente, los patronos y los trabajadores, al mismo tiempo, tienen que ser obligatoriamente miembros. Si algunos responsables sindicales pueden ser elegidos en niveles inferiores, el gobierno conserva, no obstante, el poder de dimitirlos en sus funciones y de anular las decisiones de los órganos sindicales. Las huelgas continúan siendo prohibidas, continuando en vigor las penas infligidas por actividades que son consideradas como de acción sindical legítima en los países democráticos. La Ley ignora al mismo tiempo las repetidas llamadas de la Organización Internacional del Trabajo y del grupo de estudio de la OIT, encaminadas a que la legislación y la práctica sindical en España fuesen adaptadas a las normas de la OIT.

La CIOSL denuncia la maniobra deliberada del gobierno español consistente en invitar a un grupo de estudio de la OIT a España con el fin de ayudar a restaurar los derechos sindicales, sin que este mismo gobierno tuviese la menor intención de actuar en este sentido. La CIOSL está decidida a mantener el asunto de la libertad sindical en España ante la OIT y ante otros organismos internacionales.

Un mes más tarde, concretamente el 18 de marzo de 1971, la CIOSL y la CMT emitían una declaración conjunta sobre la situación sindical de España en la que denunciaban la represión, especialmente en el País Vasco, contra militantes de UGT y STV ${ }^{47}$, la falta de autenticidad de Ley Sindical y de las elecciones sindicales, al tiempo que promovían la no participación en las mismas y el apoyo al sindicalismo libre. Nuevas quejas por la acción represiva del gobierno se sucedieron en mayo, sobre todo después de que 14 ugetistas de las federaciones de Madrid, Barcelona, Sevilla y Valladolid fueran detenidos por participar en actos el $1^{\circ}$ de mayo, y más aún al conocer el confinamiento en prisión del militante de UGT y PSOE Carlos Pardo, emigrante gallego afiliado al poderoso sindicato alemán del metal, cuya peripecia concitó la solidaridad y las denuncias ante la OIT por parte de los máximos responsables de la CIOSL y de la Federación Internacional de Trabajadores de las Industrias Metalúrgicas (FITIM) ${ }^{48}$.

Similar reacción suscitó el trágico suceso ocurrido en septiembre, cuando Pedro Patiño, obrero de la construcción de Madrid, resultó muerto tras recibir

47 El Socialista, 468, 4 de marzo de 1971: 1 y 7. Servicio de prensa de IG Metall, 351352 (29 de marzo de 1971): 1-15, FAGFITEL, Hemeroteca.

48 Telegrama de H. Buiter al director de la OIT, Wilfred Jenks, 24 de mayo de 1971, IIHS, carpeta 3055. Telegrama de la CIOSL al ministro de Justicia, 19 de mayo de 1971, IIHS, carpeta 3055. Comunicado de prensa de la CIOSL, 21 de mayo de 1971, IIHS, carpeta 3055. Servicio de prensa de IG Metall, $362-363$ (21 de junio de 1971): 1-11, FAGFITEL, Hemeroteca. Pardo fue detenido el 15 de mayo de 1971, después de ser enviado por la Federación Alemana del Metal como observador ante el resultado de las elecciones sindicales. Redactor y director de la revista Exprés Español, sus artículos habían provocado varias quejas del gobierno español. Acusado de quebrantar el artículo 132 del Código Penal, presiones alemanas lograron que saliera en libertad provisional en junio, ORTUÑO, 2005: 195-198. El Socialista, 482, 10 de junio de 1971: 2. 
un tiro por la espalda de la Guardia Civil mientras repartía octavillas entre los trabajadores de su sector, convocado a la huelga por la Federación Provincial de Construcción de UGT para reclamar mejoras en las condiciones laborales, libertad sindical, derecho a la huelga, aumento del salario mínimo, jornada semanal de 45 horas y libertad para los trabajadores detenidos en las luchas obreras $^{49}$. Junto a los telegramas de protesta enviados por el secretario general de la CIOSL al director general de la OIT y al ministro de la Gobernación, en los que lamentaba que «esta brutal acción confirma actitud represiva autoridades españolas contra todo tipo actividades sindicales legítimas $\rangle^{50}$, las intersindicales presentaron una denuncia conjunta ante el Comité de Libertad Sindical.

Al mes siguiente, como sabemos, era la fábrica de automóviles SEAT, en Barcelona, la que protagonizaba nuevos conflictos laborales, respondidos por el gobierno con una dura represión policial que provocó seis heridos y varios detenidos. De inmediato, la CIOSL se dirigió a la OIT en apoyo de la protesta emitida por los trabajadores de la industria metalúrgica y solicitando al director general «que advierta al gobierno español de las graves consecuencias a que pueden dar lugar sus políticas deliberadas de represión antisindical»; la FITIM hizo otro tanto ante el ministro de Trabajo y ante la OIT, en este caso para que su director general «intervenga para poner fin a los despidos, cierres de fábricas y otras medidas represivas ${ }^{51}$. Ante todo ello, el Comité de Libertad Sindical, en su reunión de noviembre de 1971, volvió a recomendar al Consejo de Administración que llamara la atención del gobierno de España por ciertas actividades de carácter sindical de los trabajadores que continuaban siendo consideradas como delitos conforme a la legislación.

Similar reacción provocaron los graves sucesos de El Ferrol y la huelga de Michelin en Vitoria: en abril de 1972, por ejemplo, la CIOSL presentó la correspondiente queja al Comité de libertad sindical por la detención, en Vitoria y Bilbao, de varios miembros del sindicato socialista ${ }^{52}$, mientras que los terribles sucesos ocurridos en Astilleros Bazán, en Ferrol, que se saldaron con la muerte de dos trabajadores, suscitaron una protesta contundente por parte de la FITIM, a la que enseguida se sumó la CIOSL, que elevó la correspondiente queja al secretario general de la OIT ${ }^{53}$. Además del célebre «Proceso 1001»,

49 El Socialista, 495, 23 de septiembre de 1971: 1.

50 Telegramas y comunicado de la CIOSL, 14 de septiembre de 1971, IIHS, carpeta 3015.

51 El Socialista, 501, 4 de noviembre de 1971: 4. El comunicado de la Comisión Ejecutiva de la UGT denunciando estos hechos está fechado en Toulouse, el 22 de octubre de 1971.

52 Cristina Valverde, María Inés Dueñas y Josefina Anquiano en Vitoria; Justiniano Baranda, Blanca Pera y Alicia Ayala en la cárcel de Beasaín, en Bilbao, Carta del secretario general de la CIOSL a W. Jenks, director general de la OIT, 14 de abril de 1972, IIHS, carpeta 3016 .

53 Como solía ser habitual en estos casos, el Gobierno español alegó en octubre de 1974 que la intervención de la fuerza policial no fue por motivos laborales sino de orden público y 
ya citado, 1973 se abrió con nuevas críticas por la represión desatada con motivo de la huelga en los Astilleros Españoles, en Bilbao, convocada por la renovación del convenio y que se saldó con numerosas suspensiones de empleo y sueldo, así como con la detención de siete sindicalistas vascos, entre ellos Nicolás Redondo y José A. Saracíbar, que actuaron en el conflicto junto a trabajadores de filiación comunista. Este hecho tuvo especial incidencia en el 189 Consejo de Administración de la OIT, reunido en marzo, en el transcurso del cual, el presidente del grupo de trabajadores y vicepresidente de la CIOSL en Canadá, J. Morris, presentó una denuncia por la represión sindical en España esgrimiendo los casos concretos de Marcelino Camacho, Nicolás Redondo y Enrique Múgica, detenidos y condenados por su adhesión a organizaciones sindicales constituidas fuera de las reconocidas por la ley, al tiempo que solicitaba al director general de la OIT que realizara gestiones cerca del gobierno español ${ }^{54}$.

La demanda de la CIOSL, incluida en el informe del Comité de libertad sindical, fue apoyada por varios miembros del grupo de trabajadores, entre ellos Cyril Plant, del Trade Union Congress (TUC) británico, e Ivar Noren, secretario general de la Federación Internacional de Obreros Metalúrgicos (FIOM), quien a su vez elevó una dura carta al director general de la OIT denunciando la vulneración de la libertad sindical en España y la represión desatada contra los trabajadores. De igual manera, la represión policial en el conflicto en la central térmica de San Adrián de Besós, en abril, que provocó la muerte del obrero Manuel Fernández Marqués, provocó la protesta conjunta de Otto Kersten, secretario general de la CIOSL, y Jean Brüch (CMT) ante el director general de la OIT, F. Blanchard. Ambos se refirieron expresamente a la «graves sentencias de prisión» impuestas por un tribunal militar a cuatro trabajadores que participaron en los conflictos ${ }^{55}$.

en legítima defensa. En su respuesta el Comité recordó que «una prohibición general de la huelga constituye una restricción considerable de las oportunidades que se ofrecen a los sindicatos para fomentar y defender los intereses de sus miembros y del derecho de estas organizaciones a organizar su actividad». Ver Carta del secretario general de la CIOSL a W. Jenks, 15 de marzo de 1972, IIHS, carpeta 3016. Asimismo, la CIOSL contribuyó con 50.000 pesetas para ayudar a las familias de las víctimas. El comunicado de la Comisión Ejecutiva de la UGT sobre estos hechos, que calificaba como «odiosa matanza de El Ferrol», El Socialista, 521, 23 de marzo de 1972: 1.

54 Carta del secretario general de la CIOSL a Antonio García Duarte, 6 de marzo de 1973, IIHS, carpeta 3017. El Socialista, 551, 5 de abril de 1973: 8. Carta de N. Valticos, Jefe del Departamento de Normas Internacionales del trabajo, al secretario general de la CIOSL, 15 de marzo de 1973, IIHS, carpeta 3017. En agosto, la CIOSL enviará un telegrama al ministro de Trabajo, Licinio de la Fuente, e interpondrá la correspondiente queja en la OIT por el despido de Nicolás Redondo de Astilleros Españoles.

55 Carta conjunta de Otto Kersten y Jean Brüch al director general de la OIT, 12 de febrero de 1974, IIHS, carpeta 3055. El Gobierno español indicó, en comunicación de 26 de 
Con tales precedentes, la 58 Conferencia Internacional del Trabajo debatió el caso español el 12 de junio de 1973, alentada por la requisitoria de las Internacionales (CIOSL, FSM, CMT) contra el régimen franquista por estar su legislación en contradicción con las Convenciones 87 y 98 de la OIT. De esta acusación se hizo eco el grupo de trabajadores, cuyos representantes (de las Trade Unions británicas, de los sindicatos de Canadá, de la CGT francesa y de la Confederación General Italiana del Trabajo) clamaron contra la represión y la falta de libertad sindical en España: «En un país en el que no se admite la libertad sindical, los trabajadores que actúan de acuerdo con los principios de la OIT resultan ilegales y son encarcelados», señaló el delegado británico Urwin, mientras el italiano Barbón respondía al delegado español, que oponía el principio de unidad al de libertad, recordando que «no se puede hablar de unidad cuando ésta es impuesta por la ley, cuando consiste en concentrar autoritariamente en una misma asociación a trabajadores y empresarios, concepción contradictoria con el principio de tripartismo que constituye la base de la OIT» ${ }^{56}$.

\section{EL SINDICALISMO DEMOCRÁTICO ESPAÑOL SE HACE VISIBLE EN LA OIT}

El año 1974 se abrió con un acontecimiento de especial relevancia para la oposición política y sindical española, pues con ocasión de la Segunda Conferencia Regional Europea de la OIT, los sindicatos democráticos pasaron a la ofensiva y de cara a la inmediata Conferencia Internacional, FSM y CIOSL acordaron incorporar entre sus representantes en el grupo de trabajadores, respectivamente, a un militante de CCOO (Carlos Elvira) y otro de UGT (Miguel Sánchez Mazas), y aprobar dicha representación como la única de los trabajadores españoles ${ }^{57}$. A Elvira, de CCOO, lo defendió el delegado de los Trabajadores de la Unión de Repúblicas Socialistas Soviéticas (URSS), Yuri Pimenov, mientras que a Sánchez Mazas lo apoyó Fabrizia Baduel, miembro de la Confederación Italiana de Sindicatos de Trabajadores (CISL). Aunque la delegación española montó en cólera, la votación resultó unánimemente favorable — salvo, claro está, el delegado de los sindicatos verticales, Noel Zapico-, a la decisión de las intersindicales. El impacto en la opinión pública fue muy relevante.

octubre de 1976, que, en aplicación del real decreto-ley de indulto, los cuatro trabajadores habían sido puestos definitivamente en libertad: tres de ellos el 22 de mayo de 1974 y el cuarto el 31 de marzo de 1976.

56 Mundo Obrero, 14 (julio de 1973): 9.

57 MARTÍNEZ QUINTEIRO, 1997: 366-371. También en UGT: Boletín de la Unión General de Trabajadores, 345 (febrero de 1974): 2. La versión de Carlos Elvira y de CCOO, en Información Española, 108 (enero de 1974): 4; 109 (febrero de 1974): 2-3. 
En la reunión plenaria del grupo de trabajadores, celebrada el 30 de enero de 1974, Sánchez Mazas agradeció profundamente el voto unánime de los trabajadores que representaban a 30 países de la Europa Occidental, recordó el trascendental papel jugado por la UGT en la primera etapa de la OIT a través de Largo Caballero, y no tardó en denunciar la situación social y laboral de la España franquista, que además de negarse a ratificar «convenios tan fundamentales como los de libertad sindical y derecho de asociacion y negociación colectiva», trataba de dar una imagen democrática en el exterior, mientras en el interior del país «trata a sangre y fuego a los demócratas y sobre todo a los obreros» $\rangle^{58}$.

Sánchez Mazas hizo un extenso alegato en contra de la represión del régimen, centrándose en el «Proceso 1001», en el juicio que aguardaba a diez militantes de USO y en los seis juicios que afectaban a más de 40 ugetistas, para los que se pedían penas de entre tres y doce años de cárcel. Esto último constituía, a su entender, el principal timbre de representatividad obrera de la central sindical socialista en España:

Como podéis comprobar, compañeros, a lo largo y a lo ancho de la península Ibérica, e incluso en el archipiélago canario, nuestra U.G.T. demuestra que es representativa de la clase obrera, con la representatividad más palpable: verse perseguida, juzgada y condenada con crueldad por luchar en favor de la organización libre y las aspiraciones de justicia de esa clase obrera.

Acto seguido, el ugetista pasó a rebatir los ataques lanzados desde el sindicato vertical asegurando que la UGT sí que apostaba por la unidad de los trabajadores, y que lo hacía a través de los comités de empresa libremente elegidos, de las plataformas unitarias de lucha democrática y de la solidaridad con todas las fuerzas obreras perseguidas; una unidad obrera que, al contrario de la que propugnaba el verticalismo oficial, se construía desde la base y era libremente elegida, no impuesta desde arriba. Su último alegato fue para reafirmar el europeísmo del sindicato socialista, explicitado en su contribución a la puesta en marcha de la CIOSL, en 1949, y en su reciente integración, como miembro fundador, en la Confederación Europea de Sindicatos.

Sánchez Mazas abundaría en estos mismos argumentos en una entrevista concedida al diario La Suisse, en la que, además de remarcar el peso internacional de la UGT, se esforzaba por subrayar la presencia efectiva del sindicato socialista en suelo español, al sostener que el trabajo de la organización en el exilio era una prolongación y una preparación del desarrollado en el interior del país:

58 La intervención de Sánchez Mazas, literal, en UGT: Boletín de la Unión General de Trabajadores, 345 (febrero de 1974): 2-4, y Exprés Español, 42 (marzo de 1974): 11-13. 
La UGT está esencialmente presente en España, donde viven nueve de los catorce miembros de su Comité ejecutivo. El número de nuestros militantes en España se ha incrementado considerablemente en estos últimos años.

En síntesis, la OIT había respondido de manera contundente «a la represión que ejerce el gobierno de Madrid sobre las organizaciones obreras», al tiempo que aportaba «un elemento de solución»a los sindicatos españoles clandestinos: la integración del movimiento obrero español al movimiento obrero de Europa ${ }^{59}$.

El optimismo del líder ugetista parecía más que justificado: en la 59 Conferencia Internacional de la OIT, celebrada en junio de 1974, el grupo de trabajadores incorporó no solo a los citados representantes de CCOO (Elvira) y UGT (Sánchez Mazas), sino también a José García, de USO, arropado por la FIOM, y a Eduardo Rojas, de STV, apoyado por la CMT. Toda la Conferencia, salvo Noel Zapico, delegado del sindicato vertical, aprobó como única representación a los miembros de las centrales democráticas ${ }^{60}$. Para dar más resonancia al caso, CCOO, UGT y USO prepararon una «Declaración común de los representantes de los trabajadores españoles en la OIT» que repasaba la historia de la persecución sindical durante el régimen de Franco y denunciaba la naturaleza y el funcionamiento del sindicato vertical. Cuando procedieron a presentarla en rueda de prensa en el exterior del Palacio de las Naciones, miembros de la delegación española arremetieron contra ellos en una agria discusión que obligó a dispersar la rueda de prensa. Esta «agresión» dio aún más relevancia y alcance al documento. Además, en el transcurso de la Conferencia se escucharon varias voces denunciando la situación española, pese a la defensa que hizo el ministro Licinio de la Fuente. Especialmente incisivos fueron Benedict, representante de la Federación Internacional de las Organizaciones de Trabajadores de la Metalurgia; el delegado de los trabajadores de Yugoeslavia; el delegado de los trabajadores de la India; y el consejero técnico portugués, Correia.

Esta tónica de presión del sindicalismo democrático ya no cesaría: a principios de 1975, reciente el resultado en las elecciones sindicales contrario al oficialismo del vertical (el 40\% de los elegidos se decantó por su reforma sin ruptura y otro $40 \%$ era de CCOO), el Comité de Libertad Sindical acogió más denuncias contra la represión franquista. Y en la 60 Conferencia Internacional del Trabajo, del 4 al 25 de junio, con Franco agonizante, los delegados españoles se sintieron acorralados. Fueron especialmente duras las intervenciones de los representantes de los trabajadores de Francia, René Salanne, que consiguió de nuevo incorporar al grupo a Miguel Sánchez Mazas, de la URSS y

59 El Socialista, 16 (tercera época), 16 de febrero de 1974: 4.

60 Cambio 16, 1 de junio de 1977: 5. 
Yugoeslavia, y otro tanto hicieron el portugués Rana y el francés Poulanne. Como señala Martínez Quinteiro, en un contexto de recuperación de las libertades en Portugal y Grecia, muchos asimilaron la situación española al Chile de Pinochet, interpretándola como una especie de excepción dictatorial. La respuesta española, por boca del ministro de Trabajo, Fernando Suárez, fue casi silenciosa. Aun así, la UGT lanzó un duro comunicado que comenzaba «Fuera de la OIT el ministro de Trabajo Español», y criticaba duramente la represión contra el movimiento obrero en España:

Mientras que en toda España $-\mathrm{y}$ sobre todo en el País Vasco, sometido a la represión del estado de excepción y al terror de comandos fascistas ('Guerrilleros de Cristo Rey') - , los trabajadores son encarcelados masivamente, torturados y asesinados, la Conferencia Internacional del Trabajo, en la que participan delegados de los trabajadores del mundo entero, escucha el falaz discurso del ministro español, con los sindicalistas verticales que le acompañan en el Palacio de las Naciones, uno de los principales responsables de la feroz represión antiobrera que se desarrolla más allá de los Pirineos.

Los trabajadores españoles emigrados, así como las fuerzas obreras y democráticas de Suiza, y los verdaderos representantes de los trabajadores del mundo entero en la Conferencia Internacional del Trabajo no pueden admitir esta escandalosa provocación. ¡Abajo los verdugos de los trabajadores! ${ }^{61}$

Con todo, las discrepancias entre UGT y CCOO no tardaron en salir a escena, no en vano al sindicato socialista no le quedaba otro remedio que esgrimir su presencia internacional y su amplia trayectoria histórica y sindical para compensar la debilidad provocada por su negativa a participar en la estrategia entrista en el sindicato vertical. Tales argumentos le valieron a $E l$ Socialista para protestar por el hecho de que la OIT recibiera a las Comisiones Obreras «en las mismas condiciones que a nuestra UGT, confundiendo a sabiendas lo que son las primeras y el papel que corresponde jugar a esta última» ${ }^{62}$. Y es que, según el periódico socialista, CCOO no era un sindicato, sino

... una serie de grupos más o menos representativos (...), las CCOO (...) se crean en el seno mismo de una empresa, con la participación de cuantos quieran participar en sus reuniones y actividades, pero sin que exista ningún compromiso orgánico entre representantes y representados, es decir, lo que Rosa Luxemburgo llamaba 'espontaneidad de las masas'. A lo más que se ha podido llegar es a la creación de una fantasmagórica coordinadora nacional con pretensiones de central sindical representativa, ya que ésta ha de tener como base los afiliados y militantes adheridos volun-

61 El Socialista, 42 (tercera época), 16 de junio de 1975: 4.

62 «UGT y CCOO: claridad ante todo», El Socialista, 18 (tercera época), 16 de marzo de 1974: 6. 
tariamente, sobre la base de un programa, regidos por unos estatutos, con una disciplina impuesta y aceptada por todos, lo que en CCOO no es el caso.

\section{CONCLUSIONES. LA OIT, UN INSTRUMENTO DE PRESIÓN A FAVOR DEL SINDI- CALISMO DEMOCRÁTICO}

A la altura de 1975, la OIT había cumplido con creces ese papel de altavoz de las críticas al régimen franquista y a su sistema sindical que le confería el sindicalismo democrático español, pues a través de su labor se había logrado desprestigiar a la OSE y dar munición a sus críticos. Además, también actuó como escudo para moderar la represión, sobre todo para los socialistas, gracias sobre todo a la influencia de la CIOSL en los gobiernos occidentales y en el Mercado Común Europeo, en el que el Régimen había solicitado entrar en 1962. Además, la CIOSL tenía más fuerza en el grupo de trabajadores de la OIT. Como reconocía no hace mucho el mismo Nicolás Redondo ${ }^{63}$ :

En una situación de conculcación de las libertades democráticas, entre ellas las sindicales, como ocurrió en la época franquista, la intervención de la OIT fue altamente positiva en una doble vertiente. Por una parte, en un considerable apoyo moral, en saber que uno no estaba solo en la lucha por la libertad sindical sino respaldado por la OIT, por millones de trabajadores (...). El otro aspecto, para mí importantísimo, era que la aplicación de los Convenios núms. 87 y 98 desnudaba al sistema franquista agudizando sus contradicciones y poniendo al descubierto su propia esencia, dejándolo sin argumentos racionales. Ante cualquier detención, ante la policía y ante los tribunales especiales de orden público, nos era mucho más fácil ampararnos en las resoluciones de la OIT sobre libertad sindical argumentando motivos sindicales que motivos políticos (...). Teniendo plena confianza en ella, en la OIT, sus resoluciones eran para nosotros, Sindicalistas de la UGT, un balón de oxígeno, una referencia en la lucha diaria por las libertades democráticas.

Durante los primeros años de la Transición, el papel de la OIT, de la CIOSL y de la propia UGT resultó fundamental para propiciar la ruptura sindical. La aprobación, el 15 de diciembre de 1976, en referéndum, de la Ley para la Reforma Política, que en su artículo 1 disponía que la soberanía emana del pueblo y que «los derechos de la persona son inviolables y vinculan a todos los órganos del Estado», posibilitó la reforma sindical, explicitada en la «Ley 19/1977, de 1 de abril sobre regulación del derecho de asociación sindical» y en el «Real Decreto Ley 17/1977, de 4 de marzo, sobre relaciones de trabajo». De esta forma, el Ministerio de Relaciones Sindicales de Enrique de la Mata procedía a adecuar la legislación sindical española a las directrices de

63 En Voces por la libertad sindical, 112/3 (1998): 41-42. 
la OIT, especialmente a los convenios 87 y 98 , y a la necesidad de desmantelamiento o ruptura con la OSE ${ }^{64}$.

\section{BiBLIOGRAFÍA:}

Aroca Mohedano, Manuela, Internacionalismo en la historia reciente de UGT, 19711986: del tardofranquismo a la estabilización de la democracia, Madrid, Cinca, 2011.

Aroca Mohedano, Manuela, «La Unión General de Trabajadores durante el tardofranquismo: de la reivindicación histórica a la conquista del espacio sindical», en Manuela Aroca Mohedano (dir. y coord.), El sindicalismo socialista y la recuperación de la democracia (1970-1994), Madrid, F. Largo Caballero/Cinca, 2014: 15-52.

Babiano Mora, José, Emigrantes, cronómetros y huelgas. Un estudio sobre el trabajo y los trabajadores durante el franquismo, (Madrid 1951-1977), Madrid, Siglo XXI, 1995.

Balfour, Sebastián, La dictadura, los trabajadores y la ciudad. El movimiento obrero en el Área Metropolitana de Barcelona (1939-1988), Valencia, Alfons el Magnanim, 1994.

Benito del Pozo, Carmen, La clase obrera asturiana durante el franquismo, Madrid, Siglo XXI, 1993.

Camacho, Marcelino, Confieso que he luchado. Memorias, Madrid, Temas de Hoy, 1990.

Domenech, Xavier, Clase obrera, antifranquismo y cambio político, Madrid, La Catarata, 2008.

Fishman, Robert M., Working-class Organization and the Return to Democracy in Spain, London, Cornell University Press, 1990.

García Delgado, José Luis y Jiménez, Juan Carlos, Un siglo de España. La economía, Madrid, Marcial Pons, 1999.

Giménez Martínez, Miguel Ángel, El Estado franquista. Fundamentos Ideológicos, bases legales y sistema institucional, Madrid, Centro de Estudios Políticos y Constitucionales, 2014.

González, Manuel Jesús, La economía política del franquismo (1940-1970). Dirigismo, mercado y planificación, Madrid, Tecnos, 1979.

Ludevid, Manuel, Cuarenta años de sindicato vertical. Aproximación a la Organización Sindical Española, Barcelona, Laia, 1976.

Maravall, José María, Dictadura y disentimiento político. Obreros y estudiantes bajo el franquismo, Madrid, Alfaguara, 1979.

Martínez Cobo, Carlos y Martínez Cobo, José, «El Congreso de la UGT y la renovación del PSOE», en Abdón Mateos y Alicia Alted (coords.), La oposición al Régimen de Franco, tomo 2, Madrid, UNED, 1990: 599-609.

64 VILLÁN DURÁN, 114 (1977): 97-115.

Hispania, 2018, vol. LXXVIII, nº. 259, mayo-agosto, págs. 439-467, ISSN: 0018-2141, e-ISSN: 1988-8368 https://doi.org/10.3989/hispania.2018.012 
Martínez Quinteiro, Esther, La denuncia del Sindicato Vertical (Tomo II). Las relaciones entre España y la OIT (1969-1975), Madrid, CES, 1997.

Martínez Serrano, José Antonio, Economía española, 1960-1980: crecimiento y cambio estructural, Madrid, H. Blume, 1983.

Mateos López, Abdón, «Europa en la política de 'presencia internacional' del socialismo español en el exilio», Espacio, Tiempo y Forma, Serie V, $H^{a}$ Contemporánea, 2 (Madrid, 1989): 339-358.

Mateos López, Abdón, «La era Solís y la Organización Internacional del Trabajo», Espacio, Tiempo y Forma. Serie V. Historia Contemporánea, 8 (Madrid, 1995): 295-329.

Mateos López, Abdón, La denuncia del Sindicato Vertical (Tomo I). Las relaciones entre España y la OIT (1939-1969), Madrid, CES, 1997a.

Mateos López, Abdón, «El retorno de España a la Organización Internacional del Trabajo: la persistencia del ostracismo, 1956-1960», Historia Contemporánea, 16 (Vizcaya, 1997b): 201-218.

Mateos López, Abdón, Exilio y clandestinidad. La reconstrucción de UGT, 19391977, Madrid, UNED, 2001.

Mateos López, Abdón, Historia de la UGT. Contra la dictadura franquista, 19391975, Madrid, Siglo XXI, 2008.

Mateos López, Abdón y Soto Carmona, Álvaro, El final del franquismo, 1959-1975. La transformación de la sociedad española, Madrid, Historia 16, 1997.

Mateos López, Abdón y Soto Carmona, Álvaro, El franquismo. Desarrollo, tecnocracia y protesta social, 1959-1975, Madrid, Arlanza, 2006.

Molinero, Carme e Ysàs, Pere, Productores disciplinados y minorías subversivas. Clase obrera y conflictividad laboral en la España franquista, Madrid, Ed. Siglo XXI, 1998.

Ortuño, Pilar, Los socialistas europeos y la Transición española (1959-1977), Madrid, Marcial Pons, 2005.

Pérez Ledesma, Manuel y Saz Campos, Ismael (coords.), Del Franquismo a la Democracia, 1939-2013, Madrid, Marcial Pons, 2014.

Rodgers, Gerry, Lee, Eddy, Swepston, Lee y Van Daele, Jasmien, La Organización Internacional del Trabajo y la lucha por la justicia social, 1919-2009, Ginebra, OIT, 2009.

Ruiz, David (dir.), Historia de Comisiones Obreras (1958-1988), Madrid, Siglo XXI, 1993.

Sánchez López, Rosario y Nicolás Marín, María Encarna, «Sindicalismo vertical franquista: la institucionalización de una antinomia (1939-1977)», en David Ruiz (dir.), Historia de Comisiones Obreras (1958-1988), Madrid, Ed. Siglo XXI, 1993.

Saz Campos, Ismael (dir.), dossier «Crisis y descomposición del franquismo», Ayer, 68 (Madrid, 2007).

Soto Carmona, Alvaro (dir.), Clase obrera, conflicto laboral y representación sindical (Evolución socio laboral de Madrid, 1939-1991), Madrid, GPS/Unión Sindical de Madrid de CCOO, 1994. 
Soto Carmona, Álvaro, «Auge y caída de la Organización Sindical Española», Espacio, Tiempo y Forma. Serie V. Historia Contemporánea, 8 (Madrid, 1995): 247-276.

Soto Carmona, Álvaro, «Huelgas en el franquismo: causas laborales-consecuencias políticas», Historia Social, 30 (Valencia, 1998): 39-63.

Soto Carmona, Álvaro, ¿Atado y bien atado? Institucionalización y crisis del franquismo, Madrid, Biblioteca Nueva, 2005.

Townson, Nigel, España en cambio. El segundo franquismo, Madrid, Siglo XXI, 2009.

Villán Durán, Carlos, «Ley 19/1977, de 1 de abril, sobre regulación del derecho de asociación sindical y la ratificación por España de los convenios núms. 87 y 98 de la Organización Internacional del Trabajo», Revista de Política Social, 114 (Madrid, 1977): 97-115.

Vega García, Rubén (ed.), Las huelgas de 1962 en Asturias, Gijón, Trea, 2002a.

Vega García, Rubén, Las huelgas de 1962 en España y su repercusión internacional, Gijón, Trea, 2002b.

Wright, Alison, La economía española, 1959-1976, Zaragoza, Heraldo de Aragón, 1980.

Ysàs, Pere, «El Régimen franquista frente a la oposición», Cuadernos de la España Contemporánea. Universidad San Pablo CEU, 3 (Madrid, 2007): 5-22.

Recibido: $19 / 12 / 2016$

Aceptado: 09/05/2018 